\title{
FAKE NEWS E DEMOCRACIA: CONTRIBUIÇÕES DA SEMIÓTICA DISCURSIVA ACERCA DA VERDADE E DA INFORMAÇÃO NA INTERNET
}

\author{
Marcos da Veiga Kalil Filho
}

\begin{abstract}
RESUMO
As fake news consistem em procedimento de propagação de conteúdos falsos em que o apagamento ou a dissimulação da autoria representa estratégia comum para a eficácia da comunicação. $\mathrm{O}$ reconhecimento de seu impacto nos meandros democráticos exige das teorias do discurso um esforço de compreensão do fenômeno. O presente trabalho discute a problemática com base no arcabouço teórico-metodológico da semiótica discursiva.
\end{abstract}

PALAVRAS-CHAVE: fake news; semiótica discursiva; regimes de crença.

Recebido em: 29/05/19

Aprovado em: 18/09/19

m maio de 2019, a empresa sul-coreana de tecnologia Samsung anunciou a nova habilidade de seu algoritmo, capaz de simular, de forma realista, o movimento de um rosto com base em apenas uma foto (BATTAGLIA, 2019). As demonstraçóes em vídeo destacaram quadros famosos, como a "Mona Lisa", conversando e balançando o rosto e a cabeça naturalmente. O

a Doutorando e Mestre em Estudos de Linguagem pela Universidade Federal Fluminense com bolsa concedida pela Coordenação de Aperfeiçoamento de Pessoal de Nível Superior - Brasil (CAPES). Membro do SeDi - Grupo de Pesquisa em Semiótica e Discurso. Jornalista, formado pela Universidade Federal Fluminense. Advogado, formado pelo Ibmec/RJ. Contato: marcoskalil@outlook.com. 
feito tecnológico baseia-se no estudo de Zarkharov et al (2019) pela Cornell University, cujo resultado lançou renovadas preocupaçôes com relação aos impactos da tecnologia sobre a democracia no mundo.

A novidade inscreve-se na discussão sobre as deepfakes (em tradução livre, "falsificaçóes profundas"), expressão que conjuga o termo deep learning ("aprendizado profundo", ligado ao machine learning, acúmulo de conhecimento por parte de um banco de dados, possibilitando sua tomada de decisáo por uma inteligência artificial) com fake, de falso (RIDLEWSKI, 2019). Trata-se de softwares com a capacidade de gerar vídeos, áudios e outros textos falsos, mas que parecem absolutamente legítimos.

Em 2018, um comediante estadunidense utilizou um simples aplicativo para criar um vídeo convincente do ex-presidente Barack Obama. Na peça, a proeminente figura política dos EUA opinava acerca do filme Pantera Negra e ainda chamava o presidente Donald Trump de "um idiota total e completo" (SOARES, 2019). No cinema, técnicas similares têm sido utilizadas para recriar digitalmente versóes mais jovens de atores, como no filme Capitão América: Guerra Civil, da Disney/Marvel, em que o ator Robert Downey Jr., com seus 50 anos, aparece na película com a aparência de um adolescente.

A fabricaçáo da realidade, porém, náo fica restrita ao campo das artes. Com apenas algumas linhas de código, um programador pode colocar o rosto de um antigo parceiro amoroso em um vídeo pornô. A chamada "pornografia de vingança" ganha novos contornos. Se, antes, a revenge porn se limitava à divulgação de vídeos e fotos efetivamente trocados e performados pelos cônjuges, agora é possível criar rapidamente peças audiovisuais que simulam a intimidade do casal ou de um dos parceiros.

$\mathrm{Na}$ seara pública do debate político e da disseminação de informaçóes, essas aplicaçôes têm tido enorme impacto na condução dos humores e das percepçóes de massa. As deepfakes, de uma forma ou de outra, estariam ligadas a uma série de incidentes nas eleiçôes de diversos países. A criação de áudios, por exemplo, distribuídos pelo serviço de mensagens Whatsapp, é uma das ferramentas mais utilizadas para desmoralizar figuras públicas (G1, 2019). Com os vídeos falsos, estamos atravessando uma nova fronteira da persuasão e do efeito de sentido de realidade. Afinal, como explicar para um leigo que uma peça audiovisual fidedigna de uma personalidade política náo é verdadeira? 
As deepfakes, assim, correspondem a um instrumento eficaz de geração de fake news. Contudo, elas não são as únicas. Artifícios mais simples, como a elaboração de um site, um perfil "sósia" nas redes sociais e até mesmo um simples texto compartilhado incessantemente em plataformas de troca de mensagens, também contribuem para um estado geral de desinformação. O conjunto do que pode ser considerado fake news consiste em todo texto por meio do qual as instâncias tradicionais de mediação de informação e construção ética da verdade são questionadas paralelamente ao uso de estratégias enunciativas de apagamento ou melindre da instância de autoria — o ator da enunciação para a semiótica discursiva.

A Folha Política (FARAH, 2019), especializada em propagação de reportagens falsas na internet, funda-se na força singela e, ao mesmo tempo, poderosa da palavra "Folha" — vinculada ao imaginário de credibilidade de seu homônimo oficial — e de uma identidade visual sóbria. Na rede social de microblogging Twitter, a jornalista Mônica Bergamo viu-se maculada pela criação de um perfil fake com a mera mudança de uma letra de seu nome (Folha de São Paulo, 2019) — de “@monicabergamo” para “@monicaberganho”. Até um símbolo azul é utilizado ao lado do nome para simular a insígnia "verificada” de usuários de reputação, um efetivo problema semiótico.

Não se pode menosprezar o que representam as fake news para o jogo democrático. Estudo publicado pela organização Avaaz (PASQUINI, 2019) dá conta de que 98,21\% dos eleitores do presidente eleito em 2018 no Brasil, Jair Bolsonaro, foram expostos a uma ou mais notícias falsas durante a eleição e $89,77 \%$ acreditaram que os fatos eram verdadeiros. Relatores especiais em liberdade de expressão da Organização das Nações Unidas (ONU), da Organização dos Estados Americanos (OEA), da Organização para Cooperação e Segurança na Europa e da Comissão Africana sobre Direitos Humanos e dos Povos divulgaram, em 2017, declaração conjunta acerca dos riscos das fake news (Agência Brasil, 2019) para os direitos humanos.

A definição do que é verdade, os meios aceitáveis e os seus limites éticos para o convencimento e a divulgação de informaçóes são apenas algumas das questôes suscitadas pelas fake news. A semiótica discursiva de linha greimasiana congrega um amplo arcabouço de proposições teóricas e categorias de análise, as quais podem contribuir para esse debate. As modalidades epistêmicas 
e veridictórias (GREIMAS, 2014) discorrem sobre como a certeza e a verdade são produzidas entre quem diz e para quem se diz em cada ato de persuasão, que é a comunicação em acepção semiótica. Articuladas a uma certa memória coletiva de usos, a certeza e a verdade dependem de regimes de crença (FONTANILLE, 2015) para determinar o que é crível e o que é inacreditável (CALIL, 2019). Ainda no presente trabalho, esperamos propor, ao final, uma direção suscinta para o enfrentamento da controvérsia.

\section{Certeza e verdade: modalidades epistêmicas e veridictórias}

A verdade, para o constructo alicerçado por A. J. Greimas, é eminentemente contratual e decorre da fidúcia — " "...] toda comunicação humana, toda tratativa, mesmo que náo verbal, está fundada sobre um mínimo de confiança mútua e que ela vincula os protagonistas ao que chamamos contrato fiduciário" (GREIMAS, 2014, p. 134). Ela, portanto, é construída em cada texto, sem que isso diminua sua força. Nessa linha, a semiótica discursiva filiou-se às correntes que derrubaram o edifício da verdade universal e ontológica, e até mesmo da verossimilhança, como confirmação de um referente externo para reconhecer na crença o pressuposto de todo saber. "Percebeu-se [...] que o eu penso que, que serve de suporte para o discurso interior do sujeito, quando este quer exteriorizá-lo, não é um 'eu sei', mas um 'eu creio'. [...] o saber dito científico seria apenas um parêntese ou [...] um efeito de sentido que se constitui em condiçôes a serem determinadas" (GREIMAS, 2014, p. 128). A semiótica não se ocupa do que é a verdade, mas da maneira como o verdadeiro se faz.

Esse movimento não relativiza a verdade, mas reconhece sua dependência das estratégias enunciativas empenhadas no enunciado pelo sujeito da enunciação, composto pelos perfis de enunciador e enunciatário instaurados no texto. Cada um deles circunscreve dois fazeres importantes para o entendimento da conformação da verdade. O enunciador - "aquele que diz", análogo ao autor - empreende um fazer persuasivo em direção ao enunciatário — "para quem se diz", análogo ao leitor —, que, por sua vez, realiza um fazer interpretativo. Por estarem instaurados no texto-enunciado, enunciador e enunciatário são coautores, agem concomitantemente para a produção e atribuição dos sentidos do texto (FIORIN, 2016). 
A imagem projetada do autor, como a própria indicação de autoria da jornalista Mônica Bergamo no Twitter e o estilo discursivo jornalístico desta, junta-se às demais marcas textuais para erigir uma força de persuasão, que passa, inarredavelmente, pela crença primordial de um no outro, mas também pela delineação do que é verdade ou falsidade no interior do texto-enunciado. Por mais que estejamos na era de questionamento das instituiçóes tradicionais de informação — como, por excelência, a imprensa — as figuras-signos geradas por elas, tais como marcas, cores, identidades visuais, personagens-jornalistas, ainda possuem algum capital simbólico-semântico atinente aos valores da credibilidade. Tanto o é, que, não raro, as fake news tentam emulá-las para que o seu fazer persuasivo ganhe ao menos parte desses valores.

Do lado do enunciatário, a relação estabelecida por um sujeito da enunciação constitutivamente duplo, composto "por quem diz" e "para quem se diz", impóe uma gama de coerçóes sobre o enunciador. Se a comunicação é um fazer persuasivo, buscam-se as estratégias enunciativas que sejam mais eficazes (GREIMAS, 2014) para alcançar o enunciatário em seu fazer interpretativo. A sua imagem, então, imporá restriçóes aos elementos selecionados pelo enunciador. Mesmo fake news divulgadas pelo Whatsapp, de autoria difusa e apagada, constroem esses perfis, pois o enunciado é sempre - direcionado a um enunciatário. O que elas demonstram, ao fim, é que a verdade é também fruto da eficácia da comunicação, corolário antigo da semiótica discursiva.

A eficiência da relação entre enunciador e enunciatário depende de um "crer" mínimo. Assim, a persuasão, para a semiótica, se dá na ordem da crença em que o primeiro realiza um "fazer crer" sobre o segundo, que é, por seu turno, responsável efetivamente pelo "crer":

No eixo da comunicação (real ou "imaginária”, quando depende de um discurso interiorizado), o "crer" opóe-se ao "fazer crer" (ou persuasão) e corresponde, por conseguinte, à instância do enunciatário que exerce seu fazer interpretativo, ao passo que o "fazer crer" é obra do enunciador encarregado do fazer persuasivo. [...] sua inclusão no quadro do fazer interpretativo, 
enquanto ponto de chegada e sanção final deste, já permite verlhe um pouco melhor a problemática. De fato, o crer não é somente o fundamento da fé religiosa, mas constitui também e entre outras coisas [...] a instância crucial do discurso científico; numa visão mais ampla, o fazer crer, o qual, enquanto fazer persuasivo, não pode ser tratado independentemente do crer, constitui uma das forma principais da manipulação [...]. (GREIMAS; COURTÉS, 2013, p. 107)

Dessa forma, o enunciado manifesta um fazer persuasivo do enunciador ou, nos termos presentes, um "fazer crer" sobre o enunciatário, que, nesse sentido, realiza um "crer”, um juízo epistêmico (GREIMAS, 2014), que finaliza o seu fazer interpretativo, sancionando as posiçóes cognitivas propostas. Em consequência, o que a semiótica discursiva propóe retira a ingenuidade de certa visada sobre os processos comunicativos, trazendo à tona a dimensão da crença envolvida em todo texto, seja ele qual for.

$\mathrm{O}$ ato epistêmico designa uma operação de comparação entre o que é proposto pelo fazer persuasivo do enunciador e o que já se sabe ou se crê por parte do enunciatário, uma identificação de quem interpreta com o que é interpretado (GREIMAS, 2014). Esse movimento de reconhecimento acontece, primeiramente, por meio das modalidades epistêmicas, pelas quais o sujeito aceita, recusa, admite ou duvida da proposição representada pelo enunciador e o enunciado.

[...] toda proposição formulada pelo enunciador está assentada em uma base epistêmica que vai da afirmação à dúvida e da refutação à admissão [...] Esse ato epistêmico, entretanto, que serve de prelúdio à comunicação, não é uma simples afirmação de si, mas um passo que é dado, uma solicitação de consenso, uma proposição de contrato, aos quais o enunciatário dará continuidade com um aceite ou uma recusa. Entre essas duas instâncias e essas duas atitudes se organiza o espaço cognitivo da persuasão e da interpretação [...] (GREIMAS, 2014, p. 135) 
A certeza que afirma, a exclusão que recusa, a probabilidade que admite e a incerteza que duvida são operaçóes em que o sujeito se liga ao objeto de maneiras diferentes - ou, em outras palavras, que interpreta e julga o texto de acordo com esses quatro polos, representados abaixo, respectivamente, pela certeza (um "crer-ser", o sujeito está em conjunção com o objeto e por isso pode afirmar que é), pela incerteza (um "não crer ser", o estado de não conjunção do sujeito com o objeto, o que o leva a duvidar), pela improbabilidade (um "crer não ser", pelo qual o sujeito está em disjunção com o objeto, assim recusando sua validade), e pela probabilidade (um "não crer não ser", o sujeito em não disjunção com o objeto, o que o leva a admitir a possibilidade).

Figura 1: Modalidades epistêmicas.

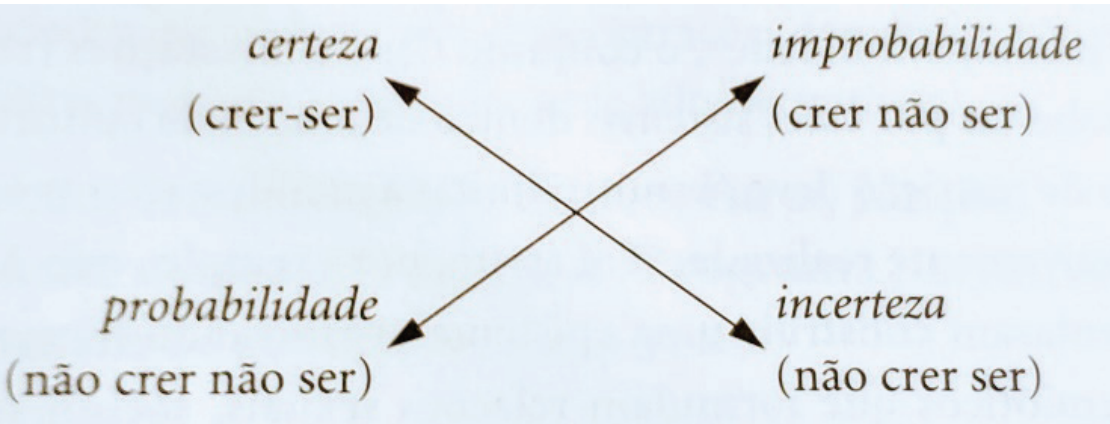

Fonte: GREIMAS; COURTÉS, 2013, p. 172.

As modalidades epistêmicas abarcam sobre a formação da certeza no ato comunicativo que compreende um fazer persuasivo e um fazer interpretativo. O que é certo confirma a existência do sujeito. O que é excluído, em forma de recusa, entra em conflito com o estatuto do sujeito e, por isso, é descartado. $\mathrm{O}$ incerto é posto em dúvida pelo sujeito que nega a certeza da conjunção com o objeto. O que é provável admite a possibilidade, situação em que um sujeito nega a disjunção com o objeto sem estar em conjunção com ele. A certeza e a improbabilidade são opostos categóricos, e a probabilidade e a incerteza são seus subcontrários, encontrados pela negação dos termos principais. 
O provável e o incerto diferenciam-se no enunciado por um ponto de vista instaurado no texto. $\mathrm{O}$ incerto, como "não certeza", implica logicamente a exclusão. Já o provável, como "não-improbabilidade", implica logicamente a certeza. Dessa forma, o provável aproxima-se mais da certeza, e o incerto da improbabilidade. Esses quatro polos podem ser construídos no texto da mesma maneira que o enunciador e o enunciatário estão inscritos no enunciado, enquanto perfis.

As fake news valem-se da certeza, mas, sobretudo, da probabilidade e da incerteza para engendrar o fazer interpretativo do enunciatário. Dado que o sujeito contemporâneo não parece se preocupar em checar as informaçôes que consome, a assunção da verdade não depende apenas da certeza, mas pode se dar também por meio da probabilidade e da incerteza. No plano empírico, podemos verificar essa hipótese quando se confronta um sujeito com o caráter incerto ou mesmo falso de uma informação e este reage: "Mas bem que poderia ser". Trata-se, ao fim e ao cabo, de estabelecer uma verossimilhança e uma confirmação do universo do sujeito - o reconhecimento e a comparação do juízo epistêmico.

Se a certeza é um "fazer-crer-certo", a verdade, para Greimas, é um "fazer-parecer-verdadeiro" (2014, p. 122). A verdade no discurso não é mais da ordem da verossimilhança ou da verdade ontológica, mas anui à veridicçáo, uma "operaçáo que se exerce como um saber sobre os objetos (do mundo)" (p. 87). Para o "juízo epistêmico definitivo" (GREIMAS; COURTÉS, 2013, p. 533), a certeza e a verdade devem ser delineadas na imanência, no interior do texto e na relação entre enunciador e enunciatário. Mais do que isso, o enunciatário deve julgar o estatuto da imanência, do "ser" do objeto, em seu contato com a manifestação, o "parecer" do objeto.

Quando a verdade prescinde de um referente externo, ela se torna um "dizer verdadeiro", ou seja, basta parecer verdadeiro para que verdadeiro seja. Por conseguinte, o discurso passa a ser "esse lugar frágil em que se inscrevem e se leem a verdade e a falsidade, a mentira e o segredo; modos de veridicçáo resultantes da dupla contribuição do enunciador e do enunciatário; suas diferentes posiçôes se estabelecem [...] na forma de um equilíbrio [...] que provêm de um acordo implícito [...] designado pelo nome de contrato de veridicção" (GREIMAS, 2014, p. 123). 
Figura 2: As modalidades veridictórias.

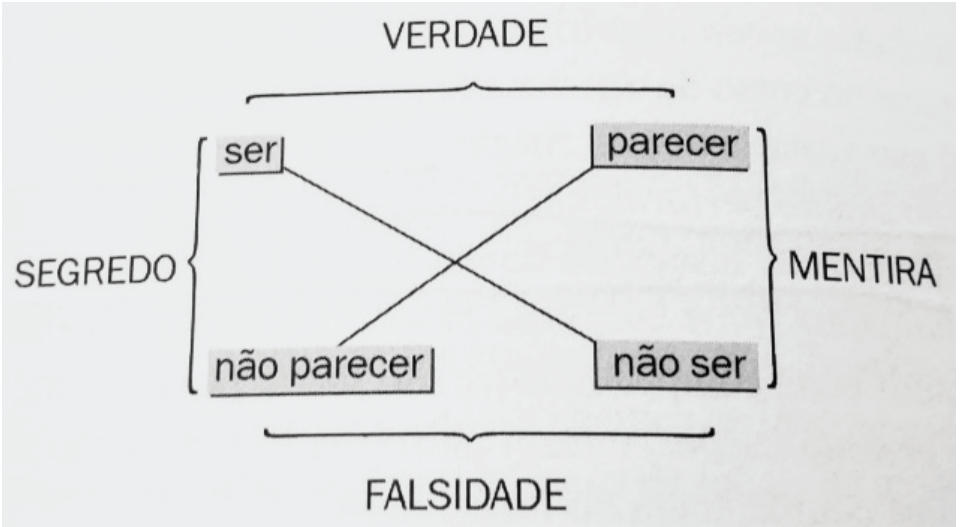

Fonte: GREIMAS, 2014, p. 66.

As modalidades veridictórias, então, inscrevem-se no texto na relação entre o fazer persuasivo e o fazer interpretativo. A verdade é um julgamento em que a manifestação parece ser e a imanência é. Um texto será falso quando não parece ser e não é. $\mathrm{O}$ objeto será mentiroso se parece ser, mas não é. As fake news muitas vezes se apresentam como um segredo - não parece, mas é —, como expressão de narrativas de conspiração e revelação do inimigo. Curioso relacionar esse fato ao comentário de Greimas acerca da "camuflagem subjetivante" (2014, p. 123), estratégia típica da veridicção pelo segredo, em que um "eu fiador da verdade" constrói um "plano anagógico a ser decifrado".

A conciliação desse modelo com o apagamento da autoria das fake news se dá por meio do entendimento que Barros (2015) proporá sobre a complexidade dos discursos na internet. Haverá sempre a presença sintática do actante da enunciação - o "eu pressuposto" do texto, o autor que pressupomos existir diante da imanência —, mas, diante da ausência semântica do ator da enunciação — a quem atribuímos figurativamente a autoria —, o que Barros entenderá como anonimato da rede mundial de computadores, propomos um passo adiante e diremos que, para as fake news, essa lacuna acaba sendo preenchida, em certas plataformas, como o Whatsapp, pela autoria de grupos de conversação ou pessoas específicas. 
O fazer persuasivo, que confere certeza e verdade ao fazer interpretativo, locupletar-se-á da ausência de um ator da enunciação para que pais, chefes, parentes, líderes religiosos e amigos, ao compartilharem as mensagens em suas redes, ocupem essa posiçấo de autoria. Esta foi, aliás, a estratégia bem-sucedida nas eleiçóes de 2018, atribuída ao presidente Jair Bolsonaro e sua equipe. As instâncias tradicionais de mediação da informação e construção de certeza e de verdade - a imprensa, a Academia e as agências estatais, todas adeptas, no discurso, à "camuflagem objetivante" - são substituídas pelo apelo subjetivo de mensagens de conhecidos. $\mathrm{O}$ "eu fiador", portanto, recai sobre quem repassa a mensagem e valoriza a proximidade em contraste com o distanciamento e a impessoalidade do jornalismo, da ciência e do Estado.

Entretanto, a atribuiçáo dos valores de verdade, falsidade, mentira ou segredo, assim como a certeza, a refutação, a probabilidade e a incerteza não são fruto de um ato individual. Seguindo a base estruturalista da semiótica discursiva, reconhece-se o caráter social das noçóes supramencionadas e, tendo como referente teórico a guinada fenomenológica, compreende-se a enunciação como dependente de uma práxis enunciativa e sua memória coletiva de uso (MANCINI, 2019). Por conseguinte, a forma como o enunciatário realiza seu fazer interpretativo se inscreve em um regime de crença (FONTANILLE, 2015).

\section{Regimes de crença e os níveis de pertinência}

Um regime de crença é um conjunto de valores depreendido de uma forma semiótica com base no confronto entre a interpretaçáo e as experiências acumuladas na memória, uma promessa que advém dessa memória e sua aceitação com base na experiência. Um regime de crença oferece ao fazer interpretativo valores como a verdade e a certeza. Ao ler um jornal, o logotipo e a formatação da informação, a objetividade e o efeito de sentido de imparcialidade fornecem ao enunciatário um leque de valores que opera, de antemáo, um fazer persuasivo direcionado à verdade e à certeza. Trata-se do regime de crença da informaçấo, oposto, por exemplo, ao regime de crença da ficcionalidade, acionado em contos literários. 
Desse modo, as modalidades epistêmicas e veridictórias, relacionadas com o crer e com o saber do enunciatário, estão imbricadas em um regime de crença. Adstrito ao conceito de práxis enunciativa, existe um regime de crença para cada nível de pertinência do percurso gerativo da expressão (FONTANILLE, 2008): figuras-signos, textos-enunciados, objetos, práticas e formas de vida.

Os profissionais do jornalismo televisivo foram historicamente impedidos de fazer propaganda de produtos porque os espectadores teriam dificuldade de compreender o que era informação e o que era comercial - uma distinção ética. As fguras-signos “jornalistas” em textos-enunciados remetem a um regime de crença da informação e acionam um fazer persuasivo imbuído das características desse universo de valores e estratégias. Informar ou vender? Essa mistura de regimes de crença parece ser uma característica da contemporaneidade tendo em vista que o enunciador contemporâneo empreende uma hibridação, visando conjugar valores e estratégias anteriormente pensados como incompatíveis.

As fake news são um exemplo dessa dinâmica: um blog pessoal com design de portal de notícias; vídeos que utilizam tanto o registro pessoal e amador em seu plano do conteúdo, quanto, no plano de expressão, estética e técnica com elevado primor profissional; esses e outros exemplos demonstram que, com a democratização das ferramentas de mídia, uma parcela significativa de pessoas consegue reproduzir figuras-signos, textos-enunciados e inseri-los em objetos e práticas semióticas que tornam difícil distinguir o seu direcionamento ético-pragmático.

Deve-se considerar, ainda, que a escrita, o áudio, a foto e a imagem televisiva compóem formas de vida com seus respectivos regimes de crença. A escrita traz consigo uma autoridade, mas pode deixar em aberto a autoria. $\mathrm{O}$ áudio, utilizado tanto no rádio, como nos trechos divulgados em aplicativos de mensagem, inicia a trajetória do efeito de sentido de realidade, seguindo, de forma ascendente, para a imagem estática e a em movimento. A foto e a imagem televisiva presentificam o que é mostrado e corroboram um regime de crença que evoca a verdade e a realidade como simulacros máximos. 


\section{Conclusões e encaminhamentos}

As deepfakes, portanto, representam risco sem precedentes para a ética pública. Já é possível criar vídeos casuais de qualquer pessoa, realizando qualquer tarefa, que "parecem verdadeiros", sem que ela, de fato, a tenha realizado. Com o desenvolvimento e a consequente ampliação do acesso a essas ferramentas, a certeza e a verdade, como efeitos de sentido construídos por estratégias enunciativas, terão aliados cada vez mais acessíveis e disponíveis. Se verdade é "dizer verdadeiro", nunca esteve tão fácil fazê-lo.

Com pouco ou nenhum esforço, algoritmos e softwares realizam o trabalho de confecção de textos, cujas marcas reconstroem regimes de crença diferentes na mesma forma semiótica: textos que congregam elementos de subjetividade e objetividade; amadorismo e profissionalismo; informação e mercantilização. Convencer-se, para Greimas, é "com-vencer", tornar o enunciatário um "vencido" do processo de argumentação (GREIMAS, 2014), a "vitória" tem-se baseado na confusão entre regimes de crença que, décadas atrás, estiveram bem delimitados na seara pública.

O enfrentamento dessa problemática deverá acontecer no âmbito da media literacy (BAUER, 2011), o que chamaremos aqui de letramento em mídia, abarcando também o letramento digital. Letramentos são o conjunto de práticas sociais ligadas às várias formas de leitura e de escrita, em sentido amplo (ROJO, 2009). Falar em letramento em mídia significa reconhecer que os veículos midiáticos requerem um arcabouço específico de habilidades e valores em sua interação e interpretação.

Para a semiótica discursiva, letramentos são práticas semióticas de produção e interpretação da significação verbal e não verbal. Por serem práticas, abarcarão também os regimes de crença e as modalidades epistêmicas e veridictórias. Desse modo, ao investir nas práticas semióticas de letramento em mídia, poderemos compreender os processos de formação dos regimes de crença perante as novas mídias e as práticas renovadas que surgem com elas. Ainda mais importante será a possibilidade de moldar esses regimes de crença à luz da ética pública e da criticidade. Na internet, devemos estar em constante estado de dúvida. 


\section{Referências}

Agência Brasil. ONU diz que "notícias falsas" representam uma preocupação global. Disponível em: http://agenciabrasil.ebc.com.br/internacional/noticia/2017-03/onu-diz-que-noticias-falsas-representam-uma-preocupacao-global. Acesso em: 26/05/2019.

BARROS, Diana Luz Pessoa de. A complexidade discursiva na internet. Cadernos de Semiótica Aplicada, 13: 13-31, São Paulo, 2015.

BATTAGLIA, Rafael. Com apenas uma foto, algoritmo da Samsung consegue criar um vídeo falso. Super Interessante, https://super.abril.com.br/tecnologia/ com-apenas-uma-foto-algoritmo-da-samsung-consegue-criar-um-video-falso/, 26/05/2019.

BAUER, Thomas. O valor público da Media Literacy. Líbero, 14: 9-22, São Paulo, 2011.

BRANDON, John. Terrifying high-tech porn: Creepy 'deepfake' videos are on the rise. Fox News, https://www.foxnews.com/tech/terrifying-high-techporn-creepy-deepfake-videos-are-on-the-rise, 26/05/2019.

BUSCH, Jenna. How they made Tony Stark younger in Captain America: Civil War. IGN, https://www.ign.com/articles/2016/09/25/how-they-madetony-stark-younger-in-captain-america-civil-war, 26/05/2019.

CALIL, Lucas. Que das trevas se faça luz: a fratura e renascimento do cânone. 2019. Tese (Doutorado em Estudos de Linguagem) - Instituto de Letras, Universidade Federal Fluminense, Niterói, 2019.

FARAH, Tatiana. Folha Política, famosa por espalhar fake news, só foi banida hoje do Facebook. Buzzfeed News, https://www.buzzfeed.com/br/tatianafarah/folha-politica-famosa-por-espalhar-fake-news-so-foi-banida, 26/05/2019.

FIORIN, José Luiz. As astúcias da enunciação. 3. ed. São Paulo: Contexto, 2016.

Folha de São Paulo. Perfis de paródias se multiplicam e confundem na internet. Disponível em: https://www1.folha.uol.com.br/poder/2019/01/perfis-de-parodias-se-multiplicam-e-confundem-na-internet.shtml. Acesso em: 27/05/2019.

FONTANILLE, Jacques. Formes de vie. Liège: Presses Universitaires de Liège, 2015. 
. Práticas semióticas: imanência e pertinência, eficiência e otimização. In: PORTELA, Jean Cristtus; DINIZ, Maria Lucia. (org.). Semiótica e Midia: textos, práticas e estratégias. Bauru: Unesp/Faac, 2008. p. 15-74.

G1. É \#FAKE aúdio atribuido a funcionário da Globo com orientaçôes contra Bolsonaro. Disponível em: https://g1.globo.com/fato-ou-fake/noticia/2018/10/22/e-fake-audio-atribuido-a-funcionario-da-globo-com-orientacoes-contra-bolsonaro.ghtml. Acesso em: 26/05/2019.

GREIMAS, Algirdas Julien. Sobre o sentido II: Ensaios semióticos. São Paulo: Nankin: Edusp, 2014.

GREIMAS, Algirdas Julien; COURTÉS, Joseph. Dicionário de semiótica. Contexto: São Paulo, 2013.

MANCINI, Renata. A enunciação tensiva em diálogo. Estudos semióticos, 15: 64-87, São Paulo, 2019.

METZ, Rachel. The fight to stay ahead of deepfake videos before the 2020 US election. CNN, https://edition.cnn.com/2019/04/26/tech/ai-deepfakedetection-2020/index.html, 26/05/2019.

PASQUINI, Patrícia. Estudo diz que 90\% dos eleitores de Bolsonaro acreditaram em fake news. Valor Econômico, https:/www.valor.com.br/politica/5965577/estudo-diz-que-90-dos-eleitores-de-bolsonaro-acreditaram-emfake-news, 26/05/2019.

RIDLEWSKI, Carlos. Inteligência artificial garante potencial destrutivo às "deepfakes", nova categoria das "fake news". Valor Econômico, https://www. valor.com.br/cultura/6272493/inteligencia-artificial-garante-potencial-destrutivo-deepfakes-nova-categoria-das-fake-news, 26/05/2019.

ROJO, Roxane. Letramentos múltiplos. Escola e Inclusão Social. São Paulo: Parábola, 2009.

SOARES, Cláudio. Deepfake: Você não vai acreditar no que Barack Obama disse neste vídeo!. Medium, https://medium.com/@cssoaresonline/deepfakevoc\%C3\%AA-n\%C3\%A3o-vai-acreditar-no-que-barack-obama-diz-nestev\%C3\%ADdeo-3892287b375a, 26/05/2019.

ZARKHAROV, Egor et al. Few-Shot Adversarial Learning of Realistic Neural Talking Head Models. Cornell University, https://arxiv.org/abs/1905.08233, 26/05/2019. 


\title{
FAKE NEWS AND DEMOCRACY: CONTRIBUTIONS OF DISCURSIVE SEMIOTICS ABOUT TRUTH AND INFORMATION
}

\begin{abstract}
Fake news consists of procedures regarding the propagation of false content. In order to achieve it, authorship is usually erased or concealed. The recognition of its impact on democracies demands an effort to further the understanding of the phenomenon. Theories of discourse can help in this vital task. The issue of fake news is discussed in this paper from the theoretical-methodological framework of discursive semiotics.
\end{abstract}

KEYWORDS: fake news; semiotics; belief systems. 
